Bouwman, R., Bomhoff, M., Robben, P., Friele, R. Is there a mismatch between the perspectives of patients and regulators on healthcare quality? A survey study. Journal of Patient Safety: 2021, 17(7), p.473-482

\begin{tabular}{|l|l|}
\hline $\begin{array}{l}\text { Postprint } \\
\text { Version }\end{array}$ & 1.0 \\
\hline Journal website & http://journals.Iww.com/journalpatientsafety/Abstract/publishahead/Is \\
\hline Pubmed link & \\
\hline DOI & $10.1097 /$ PTS.0000000000000413 \\
\hline
\end{tabular}

This is a NIVEL certified Post Print, more info at http://www.nivel.eu

\title{
Is There a Mismatch Between the Perspectives of Patients and Regulators on Healthcare Quality? A Survey Study
}

\author{
Renée Bouwman, PhD,* Manja Bomhoff, PhD, ${ }^{*}$ Paul Robben, MD, PhD, † AND \\ ROLAND FRIELE,PHD*§
}

From the *NIVEL, Netherlands Institute for Health Services Research; †Dutch Healthcare Inspectorate, Utrecht; and ¥Institute of Health Policy and Management (iBMG), Erasmus University Rotterdam, Rotterdam; and §TRANZO (Scientific Centre for Care and Welfare), Faculty of Social and Behavioural Sciences, Tilburg University, Tilburg, the Netherlands. Correspondence: Renée Bouwman, PhD, NIVEL, Netherlands Institute for Health Services Research, PO Box 1568, 3500 BN Utrecht, Netherlands (e-mail: r.bouwman@nivel.nl).

Objectives: Internationally, healthcare quality regulators are criticized for failing to respond to patients' complaints. Patient involvement is, therefore, an important item on the policy agenda. However, it can be argued that there is a discrepancy between the patients' perspective and current regulatory approaches. This study examines whether a discrepancy exists between the perspectives of patients and regulators on healthcare quality.

Methods: A questionnaire was sent to 996 people who had registered a complaint with the Dutch Healthcare Inspectorate to measure expectations of and experiences with the Inspectorate. A taxonomy was used to classify their complaints into the clinical, relationship, or management domains. Results: The response was 54\%. More complaints about clinical issues $(56 \%, \mathrm{P}=0.000)$ were investigated by the regulator than complaints about organizational (37\%) and relational issues $(51 \%)$. Patients with complaints about management issues less often indicated $(13 \%, \mathrm{P}=0.002)$ that health- care is improved by making their complaint than patients with complaints about clinical or relationship issues did (22\%-23\%). Patients who reported about relational issues with care providers attached more importance to is- suing sanctions against the care provider than other patients (mean score 2.89 versus $2.62-2.68, \mathrm{P}=0.006$ ).

Conclusions: The predominant clinical approach taken by regulators does not match the patients' perspective of what is relevant for healthcare quality. In addition, patients seem to be more tolerant of what they perceive to be clinical or management errors than of perceived relational deficien- cies in care providers. If regulators want to give patients a voice, they should expand their horizon beyond the medical framework.

Several countries such as New Zealand, the United Kingdom, and the Netherlands 
are facing problems with public trust in healthcare quality regulation.1-5 It is argued that current patient safety approaches tend to reflect a narrow medical perspective that excludes the patients' perspective, creating a discrepancy between the two.6-11 In addition, some large-scale incidents such as the Mid Staffordshire National Health Service trust scandal, where patients complaints were not responded to, have further inflamed this debate. ${ }^{5,12}$ When evaluating that case, it was recommended that openness and transparency about concerns must be ensured and that a greater role should be given to complaints within the regulatory process. ${ }^{13}$ The Care Quality Commission has expressed a commitment to pay more attention to patients' complaints in its regulation policies. ${ }^{14}$ In other countries, similar developments can be seen. Regulators have expressed a greater commitment to improving responses to complaints and giving patients a greater voice. ${ }^{4,13-17}$

However, if regulators want to involve patients and their complaints in their policies, a clearer understanding of the potential existence of discrepancies between the two perspectives is needed, either in terms of issues that are considered relevant or in terms of providing information on the effects of reporting a complaint. This could help create solutions that improve responses to complaints and patient satisfaction. This study examines whether there are discrepancies between the perspectives patients and regulators and what they imply. We studied to what degree the evaluation procedures and responses of a regulator to complaints of various natures (clinical, e.g., related to purely medical subjects, and nonclinical, e.g., related to organizational or relational subjects) presented by patients match the patients' perspectives on the relevance and perceived effects of their complaints. Complaints received by the Dutch healthcare quality regulator (more information in Box 1) are used as a case study.

We aim to answer the following questions:

- Is there a difference in patients' expectations of a regulatory authority between patients with complaints that are clinical and nonclinical in nature?

- Which complaints (clinical and nonclinical in nature) are considered to be relevant by the regulator for further investigation and does this match the patients' perspective?

- How do patients with clinical and nonclinical complaints perceive the effects of their complaints on healthcare quality and does this match their expectations?

\section{METHODS}

This study draws upon newly collected data and instruments used in previous research. ${ }^{18} \mathrm{~A}$ taxonomy was used to determine the nature of the complaints. 
Furthermore, we submitted a survey to patients who reported complaints to the Inspectorate, to measure their expectations and experiences with reporting their complaint. Information about which complaints were investigated further by the Inspectorate gave us insights into the relevance of complaints for healthcare quality from the regulator's perspective.

\section{Selection of the Study Population}

A survey was sent to all people $(n=996)$ who submitted a com- plaint to the Inspectorate between August and November 2012 or between April and August 2013. The selection of two different periods was helpful in preventing contextual factors (such as media exposure after incidents) having too much influence on patients' perceptions of the Inspectorate. Furthermore, numbers of respondents to analyze differences between subgroups within the study population (age, sex, educational level, investigated versus not investigated, and subgroups of complaints with different subjects) would be sufficient.

- Several inclusion criteria were formulated:

- The complaint must have been submitted by a member of the public/patient (or relative), not a care provider

- The complaint must be about healthcare (so general questions or complaints about the Inspectorate itself were excluded)

- If a complaint was further investigated by the Inspectorate, the investigation of the Inspectorate had to be closed, and the complainant had to have been informed about the closure by letter, so as to minimize the risk of respondents assuming that their response would have an impact on the handling of their complaint.

- An employee of the Inspectorate ensured the complaints met the inclusion criteria.

Two reminders were sent. After those, the response rate was 44\%. An abridged survey was, therefore, sent to non-responders.

In total, 67 respondents dropped out because their addresses were incorrect, the person had moved, or the person died. Thirty-three people who filled out the survey were left out of the analyses because they were included in a special intervention by the Inspectorate in which extra attention was given to the complainant, which may have influenced their experiences when reporting the complaint.

\section{THESURVEY}

The design of the survey about complaints was driven by the theory of procedural, distributive, and interactional justice. ${ }^{25}$ Information about the development of the survey can be found elsewhere (see reference). ${ }^{18}$

The survey comprised the following three parts: (1) characteristics of the person and complaint (subject and severity of physical injury), (2) people's expectations when reporting to the Inspector- ate, and (3) experiences with reporting. An open answer option was given to elucidate the subject of the complaints. Severity of any physical harm caused was measured on a five-point-scale $(1=$ no physical to $5=$ death $)$. The questions were in the form of statements for which respondents could indicate the importance of the specific statement. Immediately afterward, respondents were asked how much they felt that these statements actually applied (experiences).

Respondents' expectations making the complaint (from "not important" to "most 
Bouwman, R., Bomhoff, M., Robben, P., Friele, R. Is there a mismatch between the perspectives of patients and regulators on healthcare quality? A survey study. Journal of Patient Safety: 2017

important") and experiences with the reporting (from "no" to "yes") were measured on four-point scales. ${ }^{18}$

\section{Taxonomy}

A taxonomy was used to conduct a content analysis of the com- plaints (Table 1). This taxonomy was developed and reliability analyses were conducted for it in another study, using another complaint sample than used in the current study. The earlier study aimed to develop a standardization technique for complaint analyses covering all healthcare sectors and the setting of regulation. The taxonomy differentiates between the clinical/ care/cure domain, management/organization/logistics/planning domain, and patient-care provider relationship/communication domain. Those domains are used for grouping 6 main categories and 29 subcategories. The average reliability of the taxonomy, analyzed by using the ratings of two raters, at the level of the main categories was substantial $(\mathrm{K}=0.64)$. The taxonomy is given in the appendix. The answers of the respondents to the questions and the open answer options about the nature of the complaints were used to classify each complaint within up to three domains, main categories, and subcategories of the taxonomy (by the first author). This means that up to three domains, main categories, and subcategories can apply to one complaint.

\section{Statistical Analyses}

Statistical analyses were conducted using the software program STATAVersion 13 (Stata-Corp., College Station, TX). Background characteristics of the study population were compared with the characteristics of the Dutch population ${ }^{26}$ and are presented de- scriptively. Prevalence of the domains, main categories, and sub-categories was analyzed by counting whether they occurred at least once within the complaints. A Venn diagram was made to show the overlap between the domains. Differences in severity of physical injury between the two groups (complaints that were/were not investigated) and scores of importance of expectations between the three domains were calculated using $t$ tests. Percentages of which expectations were actually met (experiences) according to the respondents were calculated by adding scores 3 and 4 together for each variable. Differences in those experiences between the three domains, plus some detailed analyses of the subcategories of the taxonomy, were calculated using $\chi^{2}$ tests. The expectations and experience items were split across three scales, based on a factor analysis conducted in a previous study. ${ }^{18}$ Differences were considered significant if $P$ value is less than 0.05 . Cases with missing values were left out of the analyses.

It was explicitly stated that their individual answers would not be revealed to the Inspectorate. The first author kept a list of respondent codes that were also printed on each survey and the Inspectorate kept a list with the same codes and the associated names and addresses. This allowed response rates to be monitored and reminders to be sent to non-responders by the Inspectorate. The lists were destroyed after 6 months.

No personal information or medical information of the respondents was used in this study.

[TABLE 1][TABLE2]

\section{RESULTS}

First, we describe the background characteristics of respondents, types of care providers, and the nature of the complaints, plus the severity of physical injury 
related to the complaint. We then focus on what the respondents expected of reporting their complaints to the Inspectorate and if differences exist depending on the nature of the complaint. After that, we describe which com- plaints were relevant for further investigation by the Inspectorate and how the respondents with complaints of various natures experienced those responses by the Inspectorate.

\section{Background Characteristics of Respondents and Nature of Their Complaints}

The response was 54\% $(n=503,51 \%$ excluding 33 respondents who were included in the intervention). Basic study population characteristics are shown in Table 2. More than half of the respondents were female. Relatively more respondents were aged 40 to 64 years than in the Dutch population at large. The study population consisted of relatively highly educated people.

Table 3 shows the types of care that the complaints were about. Most complaints concerned hospital care (23\%), nursing homes (18\%), and mental healthcare (18\%). A relatively large proportion of complaints concerned the "other" answer option (20\%).

Examples of the answers are occupational doctors, haptonomist, and ambulance services.

\section{[TABLE 3]}

\section{What Patients Find Relevant for Healthcare Quality}

Figure 1 shows the total number of complaints reported by patients per domain. The clinical domain occurred most often $(64 \%)$

and overlapped almost equally with the other two domains. The management and relationship domains were present in four out of ten of the complaints, with a mutual overlap of $7 \%$. Only $4 \%$ of all complaints were about all three of the domains. To illustrate a complaint about the clinical domain, a patient described a safety incident as: "Got a metal on metal hip. [...] Had high concentrations of cobalt and chromium in my blood." To illustrate a com- plaint about the relationship domain, a patient described a complaint about communication: "Insufficiently informed by at- tending physician [...] about possible consequences of placing a prosthesis." An example of a complaint about the management domain is: "Admitted as a heart patient in the weekend. Unit was left unstaffed because of staff shortage."

No significant differences were found in the prevalence of the domains within the complaints with regard to age, sex, and educational level (not in table).

\section{Patients' Expectations of the Inspectorate}

Table 4 shows the average scores of importance for patients' expectations when reporting complaints, given separately for the three domains. For most respondents, it was most important that reporting their complaints leads to benefits in terms of quality of care.

Patients with complaints in the relationship domain had significantly higher expectations of specific consequences for the care provider in question compared with the other two domains $(P=0.006)$. They felt it is important that the inspectorate should have a hard-hitting conversation and that the care provider should be punished or banned from working. Detailed analyses showed that especially patients who reported about care providers not listening/not taking seriously, about rude attitudes, or about abuse found it more important that sanctions should follow compared with the remaining patients (not in table, $P=0.000-0.02$ ). 
found between the average score of self-reported severity of physical injury in investigated (mean $=2.5$ ) and non-investigated com- plaints ( mean $=2.3$ ).

Figure 2 shows the total number of complaints for each single domain and those overlapping two or three domains, as well as the number of investigated complaints. Most complaints concerned the clinical domain, and a greater proportion of clinical com- plaints were investigated by the Inspectorate $(56 \%, P=0.000$, not in table) than in the relationship (41\%) and management domains (37\%).

In addition, the average score of severity of physical injury in complaints about the clinical domain was significantly higher $(2.8, P=0.001$, not in table) than in the other domains. In-depth analyses of the subcategories showed that complaints coded as safety incidents and title misuse were investigated significantly more often than the other complaints $(P=0.001-0.05$, not in table). Figure 2 also shows that fewer complaints were handled when a complaint concerns a second and/or third domain besides the clinical or when it concerns exclusively the relationship or management domain (or both of those).

\section{Patients' Experiences With the Inspectorate}

Table 5 shows the experiences patients had with reporting their complaint and the responses of the Inspectorate. For the items on the benefits for quality of healthcare, patients complaining about management issues reported significantly fewer positive experiences compared with the other patients $(P=0.002-0.01)$. Detailed analyses show that these effects mostly concern com- plaints about finances, inappropriate behavior, insufficient/ unqualified personnel, and insufficient compliance with legislation/ directives $(P=0.01-0.04)$.

Positive experiences are obviously related to whether com- plaints are investigated: patients with complaints that were investigated more often report that theircomplaint led to benefits for quality of care $(P=0.000-0.005$, not in table).

\section{DISCUSSION}

This study examined whether there are discrepancies between the perspectives of patients and regulators and what those imply. We focused on what relevance regulators and patients attach to complaints of different natures, what patients with different complaints expected of the regulator, and how the regulator reacted to different complaints.

\section{Mismatch Between What Patients and Regulators Find Relevant for Healthcare Quality}

Formally, the Inspectorate further investigates patients' com- plaints whether they are severe or point to structural problems in healthcare. ${ }^{19}$ However, this study shows divergence in the criteria playing a role in what the Inspectorate considers relevant. Com- plaints with a clinical component are more often the subject of further 
investigations by the Inspectorate, whereas management and organizational problems, such as insufficient or unqualified personnel or noncompliance with legislation, seem to be less relevant to the Inspectorate when assessing problems encountered by patients. However, according to patients, a broader scope of aspects of quality of care is relevant and can be learned. This illustrates the mismatch between the "biomedical" agenda of medicolegal bodies and "life-world" agendas of patients ${ }^{27}$ and refers to what is an ongoing discussion in research, the medical model being dominant and a leading determinant in constructing or reconstructing the context of medical harm, adverse events, complaints, and patient safety. ${ }^{7-11,28}$ It has often been argued that the current definition of medical harm excludes the non-disease-specific or nonclinical aspects that the patient may consider harmful. ${ }^{7,811}$ Patients often evaluate the care received on nonclinical aspects,

such as the interpersonal skills of the care providers ${ }^{29}$ and how care is organized ${ }^{30}$ Furthermore, what constitutes an adverse event according to patients refers not only to the original event but also to a broader array of aspects such as the aftermath of the event and how they were treated.?

These experiences suggest that if the regulators do want to give patients a voice in their policies and acknowledge the patients' perspective, a broader perspective should be adopted rather than relying heavily on a narrow medical model or letting the "clinical view" dominate.

\section{Regulator Responds Less Effectively to Patients Who Reported Organizational Issues}

The results show that patients with complaints about organizational aspects felt less often that their complaint had an effect on quality of care. This is obviously explained by the fact that fewer complaints about organizational issues are investigated further by the Inspectorate. However, no differences were seen between the nature of the complaint and the relevance for quality of care that patients attached to their complaint. Patients, therefore, seem to think that there is also a learning potential from organizational problems for care providers and the regulator.

Bismark (2015) argues that medicolegal agencies are often focused too much on handling complaints in a procedurally correct way. ${ }^{31}$ The results seem to fit with this reasoning; complaints about organizational issues do not seem to fit in the established processes and procedures of the Inspectorate, which could limit effective responses to patients, really hearing their voice and providing what theyneed. Furthermore, it could be questioned why organizational problems are deemed to be not structural and considered less relevant for the quality of care by the Inspectorate. In addition, patients may have a better view of these types of problems in healthcare than regulators do during, for instance, regulatory visits and inspections.

\section{Surprising Results About Expectations When Complaint Concerns Relational Deficiencies}

For most patients, regardless of the nature of their complaint, it is most important that their complaint has an effect on healthcare quality. Personal benefits or consequences for care providers are less important. Nevertheless, unexpected but interesting differences are observed regarding the nature of complaints and what patients want from reporting their complaint to the regulator. Patients with complaints that concern relational capabilities of care providers attach more importance to sanctions against 
the care provider in question than other patients do. Furthermore, this study shows that those patients find it very important that their sense of justice is restored. These findings are similar to what was found in other studies. Research has shown that communication subjectively perceived by patients as unsatisfactory was the main factor that made them decide to initiate legal proceedings. ${ }^{32}$ Levinson et al. ${ }^{33}$ found that physicians who received no complaints were those who provided information, asked the patient's view, and used humor.

Research among the Dutch public showed that the majority agree with a soft approach of imposing measures by regulators in cases of poor quality of care. ${ }^{34}$ However, patients, thus, seem to be less tolerant of perceived relational deficiencies of care providers than of what they perceive to be clinical or management errors. ${ }^{29}$ Regulators could take this into account when inviting patients to report their complaints and manage theirexpectations if they approach them. It could, in addition, be debated whether regulators should play a role in addressing care providers in cases of relational deficiencies. Lastly, these results could be an important indicator for care providers that they should be aware of their relational (and in particular listening) skills. Moreover, openness, apologies, and appropriate action after adverse events are essential to patients..$^{35,36}$

\section{Strengths and Limitations}

A strength of this study is the large sample size.

The response rate in this study was modest, even after sending two reminders and an abridged survey. There is, therefore, a risk of response bias. One consequence could be that the results of this study are not fully representative of the group of people who complained to the regulator. Nonresponse analysis was not possible because no characteristics of the non-respondents were available, in part due to the meticulous privacy arrangements.

Research shows that non-respondents are more likely to be members of minority groups and lower educated groups. ${ }^{37}$ No characteristics were available of the respondents who returned the abridged survey either.

Some respondents indicated that completing the survey made them uncomfortable because it revived the situation that the com- plaint was about. This could be an important reason for the non-response. Another reason could be that filing the complaint itself had already cost a great deal of effort, making people reluctant to participate. The study population is older and more highly educated than the general Dutch population. This might be explained by the fact that this specific group feel more empowered to com- plain to the regulator.

The complaints were classified using the taxonomy by only one author, do to time constraints. Therefore, there could be a risk of misclassification bias. Nevertheless, the taxonomy has already shown to be substantially reliable.

This study only includes the process of decision-making by the regulator on if a complaint needs further investigation, because the complaint is considered structural or very severe. The follow-up after this process, on potential improvement of quality of care, is outside the scope of this study. Furthermore, the analysis is based on the content of the complaint from the perspective of the patient. The clinician's perspective on a complaint may give other insights on the cause of what went wrong. For instance, a complaint about clinical decision-making may also be caused by failing information systems. This perspective is, however, not analyzed in this study, which is a limitation of the study.

It is unclear whether the results of this study also apply to other regulatory authorities. This requires further research. 
Bouwman, R., Bomhoff, M., Robben, P., Friele, R. Is there a mismatch between the perspectives of patients and regulators on healthcare quality? A survey study. Journal of Patient Safety: 2017

\section{CONCLUSIONS}

There is a mismatch between the patients' and the regulator's perspectives. Although the clinical view dominates in the regulator's perspective, patients believe that a broader scope of contextual, organizational, and relational aspects of quality of care is relevant. This clinical view limits effectively response to patients by the Inspectorate, by really hearing the patients' voices and pro- viding what they need. The nature of complaints affects patients' expectations from reporting theircomplaint to the regulator. Patients are less tolerant when their complaint concerns relational deficiencies in care providers than when they perceive it to be a clinical or management error. It could be debated whether regulators should play a role in addressing care providers for their relational deficiencies. Furthermore, these results could be an important indicator for care providers that they should be aware of their relational skills (in particular listening to patients).

To conclude, if regulators want to include the patients' perspective in their policies, they should expand their horizon taking ac- count of the needs and expectations of patients, rather than relying too much on the medical model.

\section{ACKNOWLEDGMENTS}

The authors thank the people who responded to the questionnaire. The authors also thank the employees of the Dutch Health- care Inspectorate for their cooperation. In particular, the authors thank Helene Blok for her willingness to collaborate and her contribution to this study.

Data sharing statement

The taxonomy used is published and is added as an Appendix. Other extra data include an elaborate data set on the expectations and experiences of the respondents with reporting their complaint to the Inspectorate and some general opinions about regulation of healthcare, including open answers on what their complaint was about. The extra data are available by e-mailing r.bouwman@nivel.nl.

\section{REFERENCES}

De Nationale Ombudsman. De Inspectie voor de Gezondheidszorg: een papieren tijger? Onderzoek naar het toezicht van de Inspectie voor de Gezondheidszorg op de zorg voor verstandelijk gehandicapten. [The Dutch Healthcare Inspectorate: a paper tiger? Research on the supervision of the Dutch Healthcare Inspectorate of the care for the mentally handicapped.]. Den Haag: De Nationale Ombudsman; 2009.

Dixon-Woods M, Baker R, Charles K, et al. Culture and behaviour in the English National Health Service: overview of lessons from a large multimethod study. BMJ Qual Saf. 2014;23:106-115.

Healy J, Braithwaite J. Designing safer health care through responsive regulation. Med J Aust. 2006;184:S56-S59.

Walton M, Smith-Merry J, Healy J, et al. Health complaint commissions in Australia: time for a national approach to data collection. Aust Rev Publ Aff. 2012;11:1-18.

Francis R. Report of the Mid Staffordshire NHS Foundation Trust Public Inquiry. London: The Stationery Office; 2013.

Kuzel AJ, Woolf SH, Gilchrist VJ, et al. Patient reports of preventable problems and harms in primary health care. Ann Fam Med. 2004;2: 333-340.

Ocloo JE. Harmed patients gaining voice: challenging dominant perspectives in the construction of medical harm and patient safety reforms. Soc Sci Med. 2010;71:510-516.

Ocloo JE, Fulop NJ. Developing a 'critical' approach to patient and public involvement in patient safety in the NHS: learning lessons from other parts of the public sector? Health Expect. 2012;15:424-432.

This is a NIVEL certified Post Print, more info at http://www.nivel.eu 
Bouwman, R., Bomhoff, M., Robben, P., Friele, R. Is there a mismatch between the perspectives of patients and regulators on healthcare quality? A survey study. Journal of Patient Safety: 2017

Rhodes P, Campbell S, Sanders C. Trust, temporality and systems: how do patients understand patient safety in primary care? A qualitative study. Health Expect. 2016;19:253-263.

Rhodes P, Sanders C, Campbell S. Relationship continuity: when and why do primary care patients think it is safer? Br J Gen Pract. 2014;64: e758-e764.

Sharpe VA, Faden Al. Medical Harm. Cambridge: Cambridge University Press; 2001.

De Nationale Ombudsman. Geen gehoor bij de IGZ. [No response from the IGZ.]. Den Haag: De Nationale Ombudsman 2012.

Clwyd A, Hart T. A Review of the NHS Hospitals Complaints System: Putting Patients Back in the Picture. London: Department of Health; 2013.

CQC. Complaints matter. Journal [serial on the Internet]. 2014. Available at: http://www.cqc.org.uk/sites/default/files/20141208_complaints_matter_report.pdf. Accessed August 19, 2017.

Adams SA, van de Bovenkamp H, Robben P. Including citizens in institutional reviews: expectations and experiences from the Dutch Healthcare Inspectorate. Health Expect. 2015;18:1463-1473.

Braithwaite J, Makkai T, Braithwaite VA. Regulating Aged Care: Ritualism and the New Pyramid. Cheltenham: Edward Elgar Publishing Limited; 2007.

Cabinet Office (UK). Power in Peoples' Hands: Learning From the World's Best Public Services. London: Cabinet Office; 2009.

Bouwman R, Bomhoff M, Robben P, et al. Patients' perspectives on the role of their complaints in the regulatory process. Health Expect. 2016;19: 483-496.

IGZ Leidraad Meldingen. Guideline Reports. Utrecht: IGZ; 2013.

Friele RD, Kruikemeier S, Rademakers JJ, et al. Comparing the outcome of two different procedures to handle complaints from a patient's perspective. J Forensic Leg Med. 2013;20:290-295.

IGZ. Jaarbeeld 2014. Utrecht: IGZ; 2015.

De Nationale Ombudsman. Onverantwoorde zorg UMCG, Onverantwoord toezicht IGZ. Openbaar rapport over een klacht betreffende het UMCG en de IGZ te Utrecht. [Irresponsible care UMCG, irresponsible supervision IGZ. Public report on a complaint concerning the UMCG and the Dutch Health Care Inspectorate in Utrecht, the Netherlands.]. Den Haag: De Nationale Ombudsman; 2011.

Dutch House of Representatives. Report of general discussion, 33149 no. 8, March 16, 2012. Den Haag; 2012.

Francis R. Independent inquiry into care provided by Mid Staffordshire NHS Foundation Trust. January 2005-March 2009, Volume 1. London: The Stationery Office; 2010.

Tyler TR. Social justice: outcome and procedure. Int J Psychol. 2000;35: 117-125.

CBS. CBS Statline. 2013.

Greenhalgh T, Robb N, Scambler G. Communicative and strategic action in interpreted consultations in primary health care: a Habermasian perspective. Soc Sci Med. 2006;63:1170-1187.

Buetow S, Davis R, Callaghan K, et al. What attributes of patients affect their involvement in safety? A key opinion leaders' perspective. BMJ Open. 2013;3.

Schaad B, Bourquin C, Bornet F, et al. Dissatisfaction of hospital patients, their relatives, and friends: analysis of accounts collected in a complaints center. Patient Educ Couns. 2015;98:771-776

Olding M, McMillan SE, Reeves S, et al. Patient and family involvement in adult critical and intensive care settings: a scoping review. Health Expect. 2015.

Bismark MM. Learning from claims and complaints: an epidemiological approach to medical regulation. Dunedin, New Zealand: University of Otago; 2015.

Hamasaki T, Takehara T, Hagihara A. Physicians' communication skills with patients and legal liability in decided medical malpractice litigation cases in Japan. BMC Fam Pract. 2008;9:43.

Levinson W, Roter DL, Mullooly JP, et al. Physician-patientcommunication: the relationship with malpractice claims among primary care physicians and surgeons. JAMA. 1997;277:553-559.

Bouwman R, Bomhoff M, de Jong JD, et al. The public's voice about healthcare quality regulation policies. A population based survey. BMC Health Serv Res. 2015;15:325.

Mazor KM, Greene SM, Roblin D, et al. More than words: patients' views on apology and disclosure when things go wrong in cancer care. Patient Educ Couns. 2013;90:341-346.

Gallagher TH, Mazor KM. Taking complaints seriously: using the patient safety lens. BMJ Qual Saf. 2015;24:352-355.

This is a NIVEL certified Post Print, more info at http://www.nivel.eu 
Bouwman, R., Bomhoff, M., Robben, P., Friele, R. Is there a mismatch between the perspectives of patients and regulators on healthcare quality? A survey study. Journal of Patient Safety: 2017

Crow R, Gage H, Hampson S, et al. The measurement of satisfaction with healthcare: implications for practice from a systematic review of the literature. Health Technol Assess, 2002;6:1-244.

\section{BOX FIGURE AND TABLES}

\section{Box 1 information about complaints about healthcare inthe Netherlands}

The Dutch Healthcare Inspectorate is mandated by the Minis- try of Health, Welfare and Sports to regulate and monitor healthcare quality. It is not the statutory task of the Inspector- ate to handle complaints by individual patients. Other re- search already showed that patients are aware of that ${ }^{18}$ Responsibility for handling of patients' complaints lies primarily with the care providers, where patients can complain directly at complaint officers or boards. Complaints are only eligible for further investigation by the Inspectorate when complaints point to structural or very severe problems. The criteria are severe deviation from the applicable professional standards by medical professionals or other employees within the care institution, severe lack or failure of an internal quality system at a care institution, severe harm to health, a high probability of recurrence, or when care providers do not comply to the Clients' Right to Complain Act. ${ }^{19}$ This complaints act obliges care providers to install easily accessible indepen- dent complaints committees. The aim of such a committee is to focus explicitly on the legitimacy of the patient's complaint. Research has, however, shown that many patients are dissatis- fied after this procedure. ${ }^{20}$

The Inspectorate receives approximately 1500 complaints an- nually from patients of which the majority are not investigated further by the Inspectorate, given its remit. ${ }^{21}$ However, it was argued that the Inspectorate does not take patients seriously and should value patients' complaints as signaling deeper problems. ${ }^{5,12,22-24}$ It was stated in political debates that the patients and their complaints deserve more attention and should be involved in regulatory policies to reflect patients' perspectives. ${ }^{12,22,23}$ To improve responses to complaints, an independent contact point for the general public was set up to guide patients with complaints. 
TABLE 1. List of the Domains, Main Categories, and Subcategories of the Taxonomy

Clinical, care, and cure domain

Quality and safety

Safety incidents

Medication/medication errors/preference policy

Errors in diagnosis/triage/diagnostic assessment/medical judgment/assessing urgency

Inadequate record keeping

Failing equipment/material

Title misuse

Quality of care, skill, and performance/improper or unprofessional behaviour/clinical treatment

Coordination/alignment problems

Other, viz

Relationship patient-care provider domain

Communication

Incorrect/incomplete/missing information/shared decision-making

Unprofessional response to complaint

Not listening, not taking patient seriously, rude attitude.

Human rights

Abuse/sexual misconduct

Confidentiality

Consent

Discrimination

Coersion and compulsory admission...

Other patient's and human rights

Other, viz

Management, organization, logistics, planning domain

Organizational and institutional problems

Inappropriate/incorrect behavior of the organization or individuals within the organization

Unhealthy, poor, or unsafe environment/building or supporting services

Finances, invoicing, billing, costs, patient's own contribution

Insufficient/unqualified personnel or (supporting) resources present

Insufficient compliance with legislation/regulations/protocols/ guidelines and insufficient safeguarding of patients' rights

Inadequate organization/logistics/bureaucracy/govemance

Timing and accessibility

People are not able to access or get admission to care or the care provider (or cannot do so in time)

Discharge

Referral

Other, viz

Very complex problems 
TABLE 2. Background Characteristics of the Respondents Compared With the Dutch Population

\begin{tabular}{|c|c|c|}
\hline & $\begin{array}{l}\text { Respondents, } \\
\text { n }(\%)^{\dagger}\end{array}$ & $\begin{array}{c}\text { Dutch Population } \\
\text { (Aged } \geq 18 \text { y) } \\
2013, \%\end{array}$ \\
\hline Sex & 353 & \\
\hline Female & $134(62)$ & 51 \\
\hline Male & $219(38)$ & 49 \\
\hline Age, y & 353 & \\
\hline $18-39$ & $45(13)$ & 34 \\
\hline $40-64$ & $221(63)$ & 45 \\
\hline$\geq 65$ & $87(25)$ & 21 \\
\hline Educational level & 342 & \\
\hline $\begin{array}{l}\text { Low (none, primary school, } \\
\text { or prevocational education) }\end{array}$ & $87(25)$ & $30 *$ \\
\hline $\begin{array}{l}\text { Middle (secondary or } \\
\text { vocational education) }\end{array}$ & $97(28)$ & $40 *$ \\
\hline $\begin{array}{l}\text { High (professional higher } \\
\text { education or university) }\end{array}$ & $158(46)$ & $28^{*}$ \\
\hline Unknown & - & 2 \\
\hline
\end{tabular}

*These percentages applied to the Dutch population aged 15 to $65 \mathrm{y}$ in 2012.

${ }^{\dagger}$ The total number of respondents may differ because some respondents did not fill out all questions or only completed the short survey. 


\begin{tabular}{|c|c|c|}
\hline $\begin{array}{l}\text { Type of Care } \\
\text { Complaint Is About }\end{array}$ & $\begin{array}{c}\text { Complaints } \\
(\mathrm{n}=363), \mathrm{n}(\%)\end{array}$ & $\begin{array}{c}\text { No. } \\
\text { Investigated }\end{array}$ \\
\hline Hospital care & $84(23)$ & 25 \\
\hline Nursing homes/residential care & $67(18)$ & 35 \\
\hline Mental healthcare & $65(18)$ & 19 \\
\hline Drug therapy & $38(10)$ & 8 \\
\hline General practitioner & $35(10)$ & 10 \\
\hline Medical technology & $35(10)$ & 18 \\
\hline Care for the disabled & $31(9)$ & 15 \\
\hline Dental care & $33(9)$ & 15 \\
\hline Private clinic & $19(5)$ & 8 \\
\hline Home care & $13(4)$ & 4 \\
\hline Community care & $7(2)$ & 0 \\
\hline Physical therapy & $2(1)$ & 1 \\
\hline Other & $72(20)$ & 28 \\
\hline
\end{tabular}


FIGURE 1. Venn diagram of distribution of domains occurring in the complaints reported by patients (excluding complex complaints [4\%]).

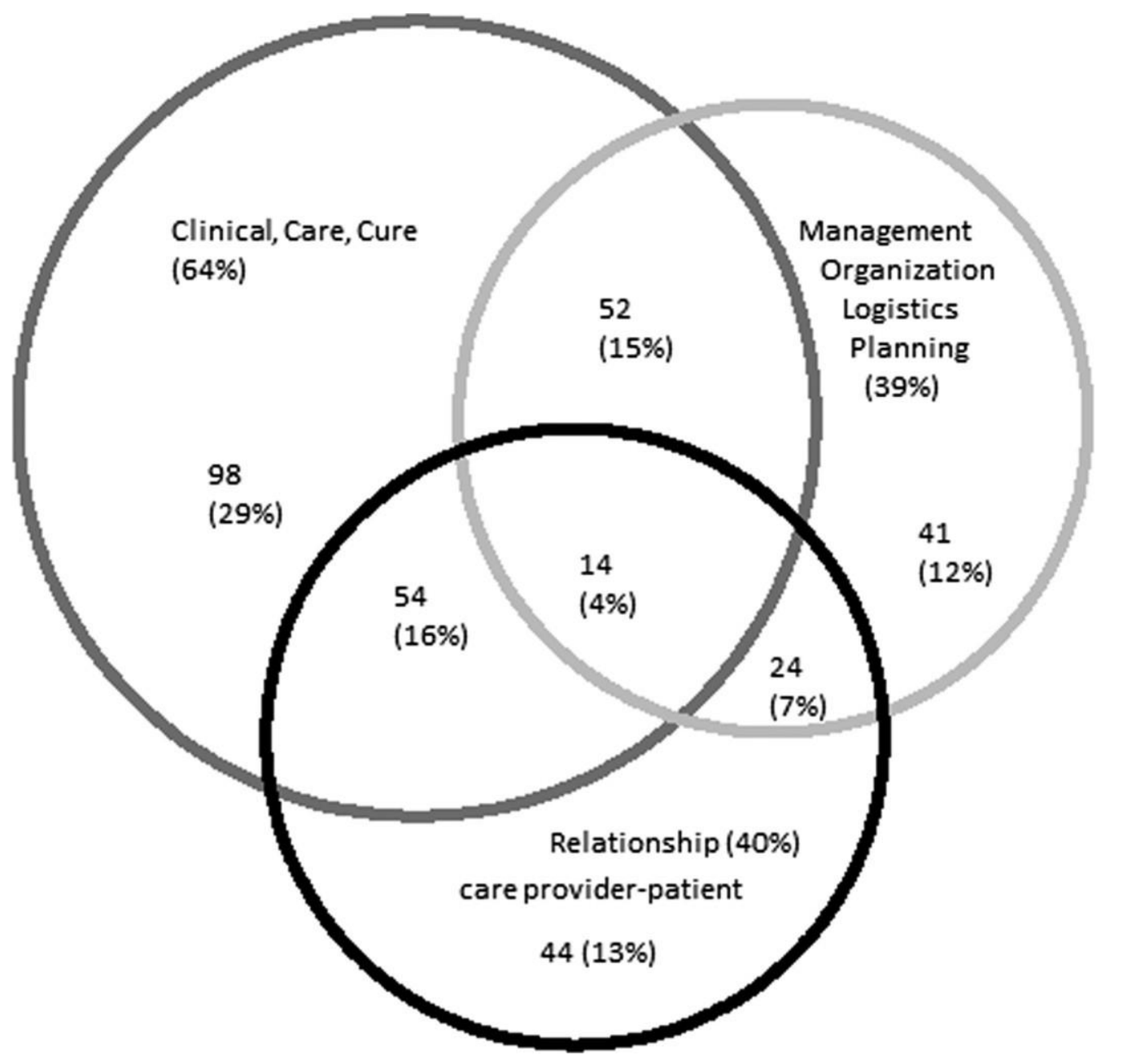


TABLE 4. Average Scores of Importance for Specific Outcome Expectations and Scale Scores Distributed for the Three Domains

Importance Scores for Each Domain:

\begin{tabular}{|c|c|c|c|}
\hline & $\begin{array}{l}\text { Clinical } \\
\text { Domain }\end{array}$ & $\begin{array}{l}\text { Relationship } \\
\text { Domain }\end{array}$ & $\begin{array}{l}\text { Management } \\
\text { Domain }\end{array}$ \\
\hline \multicolumn{4}{|l|}{ Expectations: $^{\dagger}$} \\
\hline I made my complaint to the Inspectorate because I wanted... & $\mathrm{n}=179-207$ & $\mathrm{n}=113-132$ & $\mathrm{n}=110-124$ \\
\hline Benefits for quality of healthcare in general & 3.52 & 3.58 & 3.52 \\
\hline The care institution to learn from my complaint & 3.39 & 3.51 & 3.49 \\
\hline To prevent it from happening to others & 3.61 & 3.70 & 3.56 \\
\hline To improve the quality of healthcare & 3.51 & 3.58 & 3.56 \\
\hline To improve the safety of healthcare & 3.51 & 3.51 & 3.51 \\
\hline Personal benefits & 2.68 & $2.89^{*}$ & 2.62 \\
\hline To restore my sense of justice & $2.72 *$ & $3.15^{*}$ & $2.64 *$ \\
\hline A solution to my problem & 2.81 & 3.01 & 2.78 \\
\hline To prevent it from happening to me again & 2.82 & 2.84 & 2.79 \\
\hline The damage/harm to be repaired & 2.41 & $2.72 *$ & 2.36 \\
\hline Specific consequences for care provider & 2.51 & $2.70^{*}$ & 2.43 \\
\hline Financial compensation for the damage/harm to be offered & 1.87 & 1.96 & $1.63^{*}$ \\
\hline The care provider in question to be banned from working & 2.22 & $2.50^{*}$ & 2.10 \\
\hline $\begin{array}{l}\text { The inspectorate to have a hard-hitting conversation with the } \\
\text { care provider in question }\end{array}$ & 2.79 & $3.03^{*}$ & 2.78 \\
\hline The care provider in question to be punished & 2.04 & $2.47^{*}$ & 2.04 \\
\hline The department of the care institution to be closed & 1.58 & 1.73 & 1.65 \\
\hline To do my duty by making a complaint & 2.89 & 3.04 & $2.75^{*}$ \\
\hline
\end{tabular}

*Significant difference between complaints that involve at least the specific domain compared with the complaints that do not.

${ }^{\dagger}$ The expectations were divided into three scales (benefits for quality of healthcare in general, personal benefits, specific consequences for care provider) based on a factor analysis conducted in a previous study. ${ }^{18}$ 